\title{
Metformin: A possible drug for treatment of endometrial
}

\section{cancer}

\author{
Kosuke Tsuji, Iori Kisu, Kouji Banno*, Megumi Yanokura, Arisa Ueki, Kenta Masuda, \\ Yusuke Kobayashi, Wataru Yamagami, Hiroyuki Nomura, Nobuyuki Susumu, Daisuke Aoki
}

Department of Obstetrics and Gynecology, School of Medicine, Keio University, Tokyo, Japan

Email: ${ }^{*}$ kbanno@sc.itc.keio.ac.jp

Received 22 October 2011; revised 25 November 2011; accepted 20 December 2011

\begin{abstract}
Metformin is a widely used first-line drug for treatment of type 2 diabetes mellitus. In recent years, it has been reported that administration of metformin can reduce carcinogenic risk and inhibit proliferation of cancer cells including those from glioma and breast cancer. The underlying mechanism is thought to involve increased LKB-1 phosphorylation induced by metformin, followed by LKB-1 phosphorylation and activation of AMP-activated protein kinase (AMPK), which then inhibits the mammalian target of rapamycin (mTOR) pathway and results in inhibition of cell proliferation. In endometrial cancer, metformin causes cell cycle arrest in vitro, reduces hTERT mRNA, inhibits the mTOR pathway via AMPK, and is involved in inhibition of phosphorylation of S6 ribosomal protein (S6RP). Metformin promotes expression of progesterone receptor by an action opposite to that of insulin-like growth factor-2 (IGF-2) when used in combination with medroxyprogesterone acetate. This enhances the antitumor effect and this approach may be applicable in a clinical setting.
\end{abstract}

Keywords: Metformin; Endometrial Cancer; Type 2 Diabetes Mellitus; Mammalian Target of Rapamycin (mTOR); Progesterone Receptor (PR)

\section{INTRODUCTION}

Metformin is a biguanide drug used for treatment of type 2 diabetes mellitus. In recent years, long-term administration of metformin has been found to reduce carcinogenic risk for cancers derived from various tissues. Inhibition of cellular proliferation by metformin has been reported for glioma, colon cancer, and breast cancer. Activation of AMPK and inhibition of mTOR are thought to be key events in the anti-tumor effect of metformin and

${ }^{*}$ Corresponding author. studies of these molecular mechanisms are ongoing. Since endometrial cancer is commonly and intimately related to obesity, type 2 diabetes, and insulin resistance, the inherent action of metformin on metabolic regulation may improve the prognosis of patients with this cancer, and metformin may have direct antitumor effects at the cellular level, similarly to those for other tumors. In this review, the effects of metformin on various cancers are discussed, with a focus on potential clinical application in treatment of endometrial cancer.

\section{METFORMIN TREATMENT FOR TYPE 2 DIABETES}

Metformin is a common orally available biguanide drug that is used for treatment of type 2 diabetes. Metformin is normally prescribed at the time of diagnosis of type 2 diabetes as the first-line drug, along with lifestyle guidance $[1,2]$. Its effects include inhibition of insulin-dependent gluconeogenesis in the liver, promotion of incorporation of glucose into peripheral cells through improvement of insulin sensitivity, and reduction of free fatty acids in blood by inhibiting lipolysis [3-5]. Metformin also promotes consumption of glucose in the gastrointestinal tract and the resulting lactate is used for gluconeogenesis in the liver, which may lead to an unfavorable side effect of hypoglycemia that is more serious than that with other drugs used for type 2 diabetes [3].

Treatment with metformin alone reduces glucose in fasting blood by about $20 \%$ and $\mathrm{HbAlc}$ is reduced by about $1.5 \%[3,4,6,7]$. Gastrointestinal symptoms, vitamin B12 deficiency, and lactic acidosis occur as side effects. The frequency of lactic acidosis $(9 / 100,000$ patient-years) is significantly lower than that with phenformin (40 - 64/ 100,000 patient-years) [8]. However, lactic acidosis occurs in $14 \%-27 \%$ patients with a predisposition to this condition, including those with unstable circulatory dynamics caused by shock or tissue ischemia; reduced renal function (serum $\mathrm{Cr} \geq 1.5 \mathrm{mg} / \mathrm{dL}$ (men), $\geq 1.4 \mathrm{mg} / \mathrm{dL}$ 
(women)); hepatic dysfunction, alcohol poisoning, and heart failure [9-12]. However, it is difficult to predict the risk for development of lactic acidosis based on these predispositions, particularly in patients with boundary predispositions such as compensated heart failure. Thus, administration of metformin requires consideration of the balance between the risk of occurrence of lactic acidosis and the efficacy for treatment of type 2 diabetes.

\section{METFORMIN AND CARCINOGENIC RISK}

Type 2 diabetes and insulin resistance have been reported to raise carcinogenic risks in the breast, colon, prostate gland, and pancreas [13-17]. Various studies have evaluated inhibition of carcinogenesis by metformin. Evans et al. examined 11,876 new type 2 diabetes patients and found that carcinogenic events were reduced in those who received metformin (odds ratio $=0.79$ ) [18]. Bowker et al. divided type 2 diabetes patients into three groups treated with metformin, sulfonylurea, and insulin, respectively, and found that the mortality rate due to cancer in the metformin group was about $2 / 3$ that in the sulfonylurea group [19]. In studies of about 4000 type 2 diabetes patients, Libby et al. found that the incidences of cancer were $7.3 \%$ in those treated with metformin and $11.6 \%$ in those that received an alternative treatment, with a significant difference between these groups [20,21]. These studies suggest that metformin reduces the carcinogenic risk in type 2 diabetes patients.

\section{MECHANISM OF ACTION OF METFORMIN IN CANCER CELLS}

In addition to the effect on metabolic regulation described above, metformin has a direct action that inhibits cell proliferation through activation of AMP activated protein kinase (AMPK) and resultant inhibition of mammalian target of rapamycin (mTOR) and its effector. Activation of AMPK requires LKB-1 protein, which is expressed by the LKB-1 gene, a causal gene in Peutz-Jeghers syndrome. Insulin or IGF-1 binding to a receptor on the cell membrane of tumor cells and signaling through IRS- 1 and Akt leads to mTOR activation. PTEN inhibits the signal from IRS-1 to Akt. The mTOR pathway has a plurality of downstream effectors, including S6RP, which has a role in translational regulation of proteins related to cell proliferation, and 4EBP/eiF4E, which is involved in cell cycle control. Metformin administration results in activation of LKB-1 through phosphorylation of Thr-172 of LKB-1. The activated LKB-1 phosphorylates AMPK, and the activated AMPK phosphorylates tuberous sclerosis complex 2 (TSC2). Since phosphorylated TSC2 inhibits mTOR, activation of AMPK results in inhibition of mTOR. AMPK also has a role in apoptosis regulation through $\mathrm{p} 53 / \mathrm{p} 261$, and regulation of production of fatty acids through ACC/FAS [22]. Thus, the antitumor effects of metformin are thought to occur through inhibition of mTOR via AMPK.

\section{EFFECTS OF METFORMIN IN VARIOUS CANCERS}

At the cellular level, metformin inhibits proliferation of glioma, colon cancer, breast cancer, and ovarian cancer. Glioma, a neuroectodermal tumor, is the most malignant among tumors of the central nervous system, partly due to its high motility. In an in vitro experiment, metformin inhibited metastasis of glioma cells, reduced the number of glioma cells at low concentration, and completely inhibited proliferation of glioma cells at high concentration $(8 \mathrm{mM})$. The significant increase of G0/G1 phase cells suggested that the inhibitive effect of metformin on proliferation is mainly due to cell cycle arrest. Activation of JNK, a member of the AMPK family, by metformin also caused emission of reactive oxygen species through depolarization of the mitochondrial membrane and emission of low-molecular substances such as cytochrome c, which suggests that apoptosis was induced. However, similar effects of inhibition of proliferation and induction of apoptosis by metformin did not occur in astrocytes [23].

Antitumor effects can also occur via inhibition of AMPK. In PC12 phenochromocytoma with a dominant negative AMPK, apoptosis can be induced by depletion of glucose. In addition, Compound C competitively inhibits ATP binding to AMPK and induces apoptosis in myeloma cells. Compound $\mathrm{C}$ also induces cell cycle arrest in the G2/M phase and is involved in apoptosis by activation of caspase-3 and caspase-8 [24]. Metformin and Compound $\mathrm{C}$ clearly have opposite effects on AMPK, and in simultaneous administration of these two molecules the AMPK activation effect of metformin surpassed the inhibitory effect of Compound C [25]. Collectively, these results suggest that AMPK activity is a key target in treatment of glioma, but the efficacy of metformin and Compound $\mathrm{C}$ through conflicting mechanisms indicates that the details of the antitumor effects require further study.

Some colon cancers are p53-defective and resistant to normal chemotherapy. p53 has a tumor inhibition effect, but is also important in switching of the metabolic system in a starvation state. Thus, when glucose runs low, AMPK is activated and then $\mathrm{p} 53$ is activated downstream, leading to $\beta$-oxidization of fatty acids, extracellular incorporation of glucose, and promotion of autophagy. In p53-defective cells, metabolic switching does not happen in vivo and apoptosis is further induced by metformin, whereas induction of apoptosis by metformin was not 
found in p53-positive cells [26].

Breast cancer is closely associated with type 2 diabetes, with an epidemiological study finding that type 2 diabetes raises the risk of breast cancer by $10 \%-20 \%$ [27]. In triple negative (TN) breast cancer, the estrogen receptor (ER), progesterone receptor (PR), and HER2 are not expressed. This form of breast cancer is often seen in perimenopausal women with a high waist hip ratio and BMI, and has characteristic overexpression of EGFR. TN breast cancer is particularly sensitive to metformin [28], with inhibition of proliferation of TN breast cancer cells at the same concentration as that used in treatment of type 2 diabetes. Reduction of the Ki67 index (a cell proliferation marker) by metformin occurs due to cell cycle arrest in the G1 phase and exogenous and endogenous induction of apoptosis through caspase-8 and caspase-9. The effects of metformin in common subtypes of breast cancer, such as luminal A, luminal B, and HER 2/ErbB2, have also been examined. In addition to colony formation, growth of tumors was also inhibited, and both effects occurred through non-apoptotic mechanisms. These effects are thought to be related to proteins such as cyclin D1 and E2F1, which promote the transition from G1 phase to $\mathrm{S}$ phase. Changes of tyrosine kinase signals, decreased expression of ErbB2, and activation of MAPK by metformin were also noted, and these effects were observed at the same concentration of metformin used for treatment of type 2 diabetes [29].

High expression of insulin receptor and insulin-like growth factor (IGF)-1 receptor, and signals by insulin and IGF-1 are also thought to be related to the carcinogenic mechanism of breast cancer. For example, the breast cancer cell line MCF-7 is responsive to insulin and IGF-1 [30]. To investigate whether the effect of metformin on breast cancer occurs via AMPK or is based on other mechanisms, metformin was administered after inhibition of siRNA for AMPK. Under these conditions, the inhibitive effect of metformin on cell proliferation was eliminated, indicating that the effect of metformin on breast cancer occurs through AMPK [31]. Metformin had an effect on most cell lines, but not on all, and its effect on ER-negative cells was weaker than that on ERpositive cells.

In a study of the antitumor effects of metformin in 9 types of ovarian cancer cells, Ratta et al. found that cell proliferation was clearly inhibited and that cell cycle arrest associated with decreased expression of cyclin D1 and increased expression of p21 was induced. Increased phosphorylation of AMPK and inhibition of phosphorylation of mTOR/S6RP (S6 ribosomal protein) also occurred, indicating that metformin has an antitumor effect on ovarian cancer that is similar to those for glioma, colon cancer and breast cancer. In addition, AMPK was not activated by metformin treatment of mouse embryo fibroblasts (mefs), which have a deficiency of LKB1. This shows that activation of AMPK by metformin is dependent on LKB1. Treatment of AMPK $\alpha$ (1/2)-deficient and wild-type mefs with metformin resulted in similar levels of inhibition of proliferation, which suggests that metformin acts through AMPK and through pathways that do not depend on AMPK [32].

\section{ANTITUMOR EFFECTS OF METFORMIN IN ENDOMETRIAL CANCER}

Obesity, diabetes mellitus, and insulin resistance are risk factors for type 1 endometrial cancer, with an epidemiological study showing that the risk of this cancer is 6.25 times higher in obese subjects [33]. Hyperinsulinemia and hyperandrogenemia are also risk factors for endometrial cancer, and both are frequently observed in polycystic ovary syndrome (PCOS), which itself is also considered to be a risk factor for endometrial cancer. Metformin is effective for treatment of anovulation in PCOS [34] and may have an important role in prevention of endometrial cancer. Leigh et al. examined the effects of metformin in ECC-1 and Ishikawa cells, which are both endometrial cancer cell lines [35-36]. A low concentration (about $1 \mathrm{mM}$ ) caused cell cycle arrest in G1 phase in both cell lines, while high concentrations $(2-5 \mathrm{mM})$ induced apoptosis by activation of caspase- 3 . These results show that metformin can inhibit proliferation of endometrial cancer cells. Furthermore, metformin induced phosphorylation of AMPK in a concentration-dependent manner, with resulting inhibition of phosphorylation of S6RP downstream in the mTOR pathway. ECC-1 and Ishikawa are both PTEN-positive cell lines, and thus these results show that metformin inhibits the mTOR pathway via AMPK in cells with normal PTEN, which are especially common in type 2 endometrial cancer.

The effects of metformin on telomerase were also examined [37]. Tumor cell proliferation requires maintenance of the telomere length by telomerase, and the level of hTERT mRNA is used as a marker for the activity of telomerase and cell proliferation. The hTERT mRNA level decreased in ECC-1 and Ishikawa cells after administration of metformin, which suggested that metformin has an inhibitory effect on telomerase. However, it was unclear whether the decrease in hTERT mRNA was caused by the direct action of metformin or was associated with cell cycle arrest. An earlier study using rapamycin [38] was helpful in addressing this issue. In some cell lines from endometrial, ovarian, and cervical cancer, rapamycin causes G1 arrest, inhibition of proliferation, and decreased hTERT mRNA. However, other cell lines 
showed resistance to rapamycin in that G1 arrest and inhibition of proliferation did not occur, but the hTERT mRNA level was still decreased, which indicates that a decrease of hTERT mRNA can occur independently of G1 arrest [38].

Xie et al. examined the synergistic effects of metformin and hormonal therapy on endometrial cancer [39]. Progesterone has been used in treatment of endometrial cancer for many years, but often has insufficient efficacy, mainly due to downregulation of the progesterone receptor (PR). In breast cancer, IGF-1 inhibits transcription of PR, and combined therapies of metformin and oral contraceptives improve progesterone resistance in atypical endometrial hyperplasia. Therefore, the effects of metformin on interactions between IGF and PR and in combination with medroxyprogesterone acetate (MPA) were examined in Ishikawa and HEC-1B cells. IGF-1/2 inhibited expression of PR A/B, while metformin clearly promoted this expression. In addition, IGF-2 promoted phosphorylation of Akt and p70S6K (a kinase of S6RP), while metformin promoted phosphorylation of AMPK and inhibited phosphorylation of p70S6K. Metformin also enhanced the inhibitory effect of MPA on proliferation in both cell lines. These results suggest that metformin can enhance the efficacy of MPA therapy in endometrial cancer by promoting expression of $\mathrm{PR}$ and phosphorylation of AMPK and inhibiting the associated mTOR pathway.

\section{PROBLEMS WITH USE OF METFORMIN AS AN ANTITUMOR DRUG}

Evaluation of studies on antitumor effects of metformin require careful consideration of the administered concentration. In vitro, 0.01 to $5 \mathrm{mM}$ metformin is commonly used, whereas the upper limit of the dose per day in treatment of type 2 diabetes is $2250 \mathrm{mg}$ /day, which corresponds to a blood level of $20 \mu \mathrm{M}$ [40]. Therefore, the concentration at which metformin shows antitumor effects is well above the concentration range in which it can be used safely in vivo. Thus, managing side effects may be problematic in clinical use of metformin as an antitumor agent. However, this problem requires further study, since in experiments in vitro the cancer cell lines are exposed to a super-nutrient state and receive excessive growth signals compared with cells in vivo. It is also known that the levels of metformin that accumulate in tissues are several times higher than that in blood, and thus metformin acts at a much higher level in target organs [41]. Furthermore, the efficacy of metformin for TN breast cancer has been shown to occur in the concentration range used for treatment of type 2 diabetes, as described above [28]. Potential therapy also requires ex- amination from a pharmacogenomics perspective, since the uptake and efflux of metformin is dependent on organic cation transporter 1 (OCT1) and multidrug and toxin extrusion transporter (MATE). OCT1 is polymorphic and differences in metformin uptake due to genetic variability of transporters can influence the clinical effect $[42,43]$.

\section{CONCLUSION}

Metformin is a first-line drug in treatment of type 2 diabetes that is widely used, easy to take orally, and has few side effects. Administration of metformin also reduces the risk of carcinogenesis, has preventive effects on several types of cancer, and inhibits proliferation of cancer cells. The main mechanism of action of metformin is thought to involve increased LKB-1 phosphorylation, which in turn leads to phosphorylation and activation of AMPK, which then inhibits the mTOR pathway. In endometrial cancer, metformin shows in vitro effects of cell cycle arrest; decreased hTERT mRNA levels; inhibition of phosphorylation of S6PR, a downstream effector in the mTOR pathway, by AMPK; promotion of PR expression in opposition to IGF-2; and enhancement of the antitumor effects of MPA in combination therapy. These effects suggest that clinical use of metformin as an anticancer agent is possible. However, almost all of the effects have only been shown in vitro, and many occur at a metformin concentration that is much higher than that normally used for type 2 diabetes. Therefore, side effects may be problematic in clinical use of metformin as an antitumor agent. Clarification of the molecular mechanisms underlying the antitumor effects of metformin and analysis of in vivo effects on gene expression are required for further exploration of the use of this drug as an antitumor agent.

\section{REFERENCES}

[1] Nathan, D.M., Buse, J.B., Davidson, M.B., Heine, R.J., Holmann, R.R., Sherwin, R. and Zinman, B. (2006) Management of hyperglycemia in type 2 diabetes: A consensus algorithm for the initiation and adjustment of therapy: A consensus statement from the American Diabetes Association and the European Association for the Study of Diabetes. Diabetes Care, 29, 1963-1972. doi:10.2337/dc06-9912

[2] Nathan, D.M., Buse, J.B., Davidson, M.B., Ferrannini, E., Holman, R.R., Sherwin, R. and Zinman, B. (2009) Medical management of hyperglycemia in type 2 diabetes: A consensus algorithm for the initiation and adjustment of therapy: A consensus statement of the American Diabetes Association and the European Association for the Study of Diabetes. Diabetes Care, 32, 193-203. doi: $10.2337 / \mathrm{dc} 08-9025$

[3] Bailey, C.J. (1992) Biguanides and NIDDM. Diabetes 
Care, 15, 755-772. doi:10.2337/diacare.15.6.755

[4] Bailey, C.J. and Turner, R.C. (1996) Metformin. The New England Journal of Medicine, 334, 574-579. doi:10.1056/NEJM199602293340906

[5] Stumvoll, M., Nurjhan, N., Perriello, G., Dailey, G. and Gerich, J.E. (1995) Metabolic effects of metformin in non-insulin-dependent diabetes mellitus. The New England Journal of Medicine, 333, 550-554. doi:10.1056/NEJM199508313330903

[6] (1995) United Kingdom Prospective Diabetes Study (UKPDS). 13: Relative efficacy of randomly allocated diet, sulphonylurea, insulin, or metformin in patients with newly diagnosed non-insulin dependent diabetes followed for three years. British Medical Journal, 310, 83-88. doi:10.1136/bmj.310.6972.83

[7] Wu, M.S., Johnston, P., Sheu, W.H., Hollenbeck, C.B., Jeng, C.Y., Goldfine, I.D., Chen, Y.D. and Reaven, G.M. (1990) Effect of metformin on carbohydrate and lipoprotein metabolism in NIDDM patients. Diabetes Care, 13, 1-8. doi:10.2337/diacare.13.1.1

[8] Stang, M., Wysowski, D.K. and Butler-Jones, D. (1999) Incidence of lactic acidosis in metformin users. Diabetes Care, 22, 925-927. doi:10.2337/diacare.22.6.925

[9] Horlen, C., Malone, R., Bryant, B., Dennis, B., Carey, T., Pignone, M. and Rothman, R. (2002) Frequency of inappropriate metformin prescriptions. Journal of the American Medical Association, 287, 2504-2505. doi:10.1001/jama.287.19.2504-a

[10] Calabrese, A.T., Coley, K.C., DaPos, S.V., Swanson, D. and Rao R.H. (2002) Evaluation of prescribing practices: Risk of lactic acidosis with metformin therapy. Archives of Internal Medicine, 162, 434-437. doi:10.1001/archinte.162.4.434

[11] Masoudi, F.A., Wang, Y., Inzucchi, S.E., Setaro, J.F., Havranek, E.P., Foody, J.M. and Krumholz, H.M. (2003) Metformin and thiazolidinedione use in medicare patients with heart failure. Journal of the American Medical Association, 290, 81-85. doi:10.1001/jama.290.1.81

[12] Vasisht, K.P., Chen, S.C., Peng, Y. and Bakris, G.L. (2010) Limitations of metformin use in patients with kidney disease: Are they warranted? Diabetes, Obesity and Metabolism, 12, 1079-1083. doi:10.1111/j.1463-1326.2010.01295.x

[13] Saydah, S.H., Loria, C.M., Eberhardt, M.S. and Brancati, F.L. (2003) Abnormal glucose tolerance and the risk of cancer death in the United States. American Journal of Epidemiology, 157, 1092-1100. doi:10.1093/aje/kwg100

[14] Michels, K.B., Solomon, C.G., Hu, F.B., Rosner, B.A., Hankinson, S.E., Colditz, G.A. and Manson, J.E. (2003) Nurses' Health Study. Type 2 diabetes and subsequent incidence of breast cancer in the Nurses' Health Study. Diabetes Care, 26, 1752-1758. doi:10.2337/diacare.26.6.1752

[15] Will, J.C., Galuska, D.A., Vinicor, F. and Calle, E.E. (1998) Colorectal cancer: Another complication of diabetes mellitus? American Journal of Epidemiology, 147, 816-825.

[16] Everhart, J. and Wright, D. (1995) Diabetes mellitus as risk factor for pancreatic cancer: A meta-analysis. Journal of the American Medical Association, 273, 1605-1609. doi:10.1001/jama.1995.03520440059037

[17] Gapstur, S.M., Gann, P.H., Colangelo, L.A., BarronSimpson, R., Kopp, P., Dyer, A. and Liu, K. (2001) Postload plasma glucose concentration and 27-year prostate cancer mortality (United States). Cancer Causes Control, 12, 763-772. doi:10.1023/A:1011279907108

[18] Evans, J.M., Donnelly, L.A., Emslie-Smith, A.M., Alessi, D.R. and Morris, A.D. (2005) Metformin and reduced risk of cancer in diabetic patients. British Medical Journal, 330, 1304-1305. doi:10.1136/bmj.38415.708634.F7

[19] Bowker, S.L., Yasui, Y., Veugelers, P. and Johnson, J.A. (2010) Glucose-lowering agents and cancer mortality rates in type 2 diabetes: Assessing effects of time-varying exposure. Diabetologia, 53, 1631-1637. doi:10.1007/s00125-010-1750-8

[20] Libby, G., Donnelly, L.A., Donnan, P.T., Alessi, D.R. and Morris, A.D. (2009) Evans JMM. New users of metformin are at low risk of incident cancer: A cohort study among people with type 2 diabetes. Diabetes Care, 32, 1620-1625. doi: $10.2337 / \mathrm{dc} 08-2175$

[21] Moore, M.A., Park, C.B. and Tsuda, H. (1998) Implications of the hyperinsulinemia-diabetes-cancer link for preventive efforts. European Journal of Cancer Prevention, 7, 89-107.

[22] Shaw, R.J., Lamia, K.A., Vasquez, D., Koo, S.H., Bardeesy, N., Depinho, R.A., Montminy, M. and Cantely, L.C. (2005) The kinase LKB1 mediates glucose homeostasis in liver and therapeutic effects of metformin. Science, 310, 1642-1646. doi:10.1126/science.1120781

[23] Isakovic, A., Harhaji, L., Stevanovic, D., Sumarac-Dumanovic, M., Starcevic, V., Micic, D. and Trajkovic, V. (2007) Dual antiglioma action of metformin: Cell cycle arrest and mitochondria-dependent apoptosis. Cellular and Molecular Life Sciences, 64, 1290-1302. doi:10.1007/s00018-007-7080-4

[24] Baumann, P., Mandl-Weber, S., Emmerich, B., Stranka, C. and Schmidmaler, R. (2007) Inhibition of adenosine monophosphate-activated protein kinase induces apoptosis in multiple myeloma cells. Anticancer Drugs, 18, 405-410. doi:10.1097/CAD.0b013e32801416b6

[25] Vucicevic, L., Misirkic, M., Janetovic, K., HarhajiTrajkovic, L., Prica, M., Stevanovic, D., Isenovic, E., Sudar, E., Sumarac-Dumanovic, M., Micic, D. and Trajkovic, V. (2009) AMP-activated protein kinase-dependent and independent mechanisms underlying in vitro antiglioma action of compound C. Biochemical Pharmacology, 77, 1684-1693. doi:10.1016/j.bcp.2009.03.005

[26] Buzzai, M., Jones, R.G., Amaravadi, R.K., Lum, J.J., DeBeradinis, R.J., Zhao, F., Viollet, B. and Thompson C.B. (2007) Systemic treatment with the antidiabetic drug metformin selectively impairs p53-deficient tumor cell growth. Cancer Research, 67, 6745-6752. doi:10.1158/0008-5472.CAN-06-4447

[27] Wolf, I., Sedetzki, S., Catane, R., Karasik, A. and Kaufman, B. (2005) Diabetes mellitus and breast cancer. Lancet Oncology, 26,103-111. doi:10.1016/S1470-2045(05)01736-5 
[28] Liu, B., Fan, Z., Edgerton, S.M., Deng, X.S., Alimova, I.N., Lind, S.E. and Thor, A.D. (2009) Metformin induces unique biological and molecular responses in triple negative breast cancer cells. Cell Cycle, 8, 2031-2040. doi:10.4161/cc.8.13.8814

[29] Alimova, I.N., Liu, B., Fan, Z., Edgerton, S.M., Dillion, T., Lind, S.E. and Thor, A.D. (2009) Metformin inhibits breast cancer cell growth, colony formation and induces cell cycle arrest in vitro. Cell Cycle, 8, 909-915. doi:10.4161/cc.8.6.7933

[30] Sachdev, D., Singh, R., Fujita-Yamaguchi, Y. and Yee, D. (2006) Down-regulation of insulin receptor by antibodies against the type I insulin-like growth factor receptor: Implication for anti-insulin-like growth factor therapy in breast cancer. Cancer Research, 66, 2391-2402. doi:10.1158/0008-5472.CAN-05-3126

[31] Zakikhani, M., Dowling, R., Fantus, G., Pollak, M. and Sonenberg, N. (2006) Metformin is an AMP kinase-dependent growth inhibitor for breast cancer cells. Cancer Research, 66, 10269-10273. doi:10.1158/0008-5472.CAN-06-1500

[32] Rattan, R., Giri, S., Hartmann, L.C. and Shridhar, V. (2011) Metformin attenuates ovarian cancer cell growth in an AMP-kinase dispensable manner. Journal of Cellular and Molecular Medicine, 15, 166-178. doi:10.1111/j.1582-4934.2009.00954.x

[33] Calle, E.E., Rodriguez, C., Walker-Thurmond, K. and Thun, M.J. (2003) Overweight, obesity, and mortality from cancer in a prospectively studied cohort of U.S. adults. The New England Journal of Medicine, 348, 1625-1638. doi:10.1056/NEJMoa021423

[34] Dronavalli, S. and Ehrmann, D.A. (2007) Pharmacologic therapy of polycystic ovary syndrome. Clinical Obstetrics and Gynecology, 50, 244-254. doi:10.1097/GRF.0b013e31802f35a0

[35] Mutter, G.L., Lin, M.C., Fitzgerald, J.T., Kim, J.B., Baak, J.P., Lees, J.A., Weng, L.P. and Eng, C. (2000) Altered PTEN expression as a diagnostic marker for the earliest endometrial precancers. Journal of the National Cancer
Institute, 92, 924-930. doi:10.1093/jnci/92.11.924

[36] Lu, K.H., Wu, W., Dave, B., Slomovitz, B.M., Buruke, T.W., Munsell, M.F., Broaddus, R.R. and Walker, C.L. (2008) Loss of tuberous sclerosis complex-2 function and activation of mammalian target of rapamycin signaling in endometrial carcinoma. Clinical Cancer Research, 14, 2543-2450. doi:10.1158/1078-0432.CCR-07-0321

[37] Cantrell, L.A., Zhou, C., Mendivil, A., Malloy, K.M., Gehrig, P.A. and Bae-Jump, V.L. (2010) Metformin is a potent inhibitor of endometrial cancer cell proliferationImplications for a novel treatment strategy. Gynecologic Oncology, 116, 92-98. doi:10.1016/j.ygyno.2009.09.024

[38] Zhou, C., Gehrig, P.A., Whang, Y.E. and Boggess, J.F. (2003) Rapamycin inhibits telomerase activity by decreasing the hTERT mRNA level in endometrial cancer cells. Molecular Cancer Therapeutics, 2, 789-795.

[39] Xie, Y., Wang, Y.L., Yu, L., Hu, Q., Ji, L., Zhang, Y. and Liao, Q.P. (2011) Metformin promotes progesterone receptor expression via inhibition of mammalian target of rapamycin (mTOR) in endometrial cancer cells. Journal of Steroid Biochemistry and Molecular Biology, 126, 113120. doi:10.1016/j.jsbmb.2010.12.006

[40] Scheen, A.J. (1996) Clinical pharmacokinetics of metformin. Clinical Pharmacokinetics, 30, 359-371. doi:10.2165/00003088-199630050-00003

[41] Wilcock, C. and Bailey, C.J. (1994) Accumulation of metformin by tissues of the normal and diabetic mouse. Xenobiotica, 24, 49-57. doi: $10.3109 / 00498259409043220$

[42] Koepsell, H., Lips, K. and Volk, C. (2007) Polyspecific organic transporters: Structure, function, physiologic roles, and biopharmaceutical implications. Pharmaceutical Research, 24, 1227-1251. doi:10.1007/s11095-007-9254-Z

[43] Shu, Y., Sheardown, S., Brown, C., Owen, R.P., Zhang, S., Castro, R.A., Ianculescu, A.G., Yue, L., Lo, J.C., Burchard, E.G., Brett, C.M. and Glacomini, K.M. (2007) Effect of genetic variation in the organic cation transporter 1 (OCT1) on metformin action. Journal of Clinical Investigation, 117, 1422-1431. doi:10.1172/JCI30558 